\title{
Hypoxia Preconditioning of Human MSCs: a Direct Evidence of HIF-1 $\alpha$ and Collagen Type XV Correlation
}

\author{
Elisabetta Lambertini ${ }^{a} \quad$ Letizia Penolazzi $^{\mathrm{a}} \quad$ Marco Angelozzi ${ }^{\mathrm{a}}$ \\ Leticia Scussel Bergamin ${ }^{a}$ Cristina Manferdini ${ }^{b}$ Francesco Vieceli Dalla Sega ${ }^{c}$ \\ Francesca Paolella $^{\mathrm{b}}$ Gina Lisignolib Roberta Piva ${ }^{\mathrm{a}}$ \\ aDepartment of Biomedical and Specialty Surgical Sciences, University of Ferrara, Ferrara, blstituto \\ Ortopedico Rizzoli IRCCS, Laboratory of Immunorheumatology and Tissue Regeneration, Bologna, \\ 'Maria Cecilia Hospital, GVM Care \& Research, E.S. Health Science Foundation, Cotignola, Italy
}

\section{Key Words}

Hypoxia preconditioning - Mesenchymal stromal cells • Osteopotency • Collagen type XV • HIF-1 $\alpha$

\begin{abstract}
Background/Aims: Mesenchymal stromal cells (MSCs) hold considerable promise in bone tissue engineering, but their poor survival and potency when in vivo implanted limits their therapeutic potential. For this reason, the study on culture conditions and cellular signals that can influence the potential therapeutic outcomes of MSCs have received considerable attention in recent years. Cell maintenance under hypoxic conditions, in particular for a short period, is beneficial for MSCs, as low $\mathrm{O}_{2}$ tension is similar to that present in the physiologic niche, however the precise mechanism through which hypoxia preconditioning affects these cells remains unclear. Methods: In order to explore what happens during the first 48 $\mathrm{h}$ of hypoxia preconditioning in human MSCs (hMSCs) from bone marrow, the cells were exposed to $1.5 \% \mathrm{O}_{2}$ tension in the X3 Hypoxia Hood and Culture Combo - Xvivo System device. The expression modulation of critical genes which could be good markers of increased osteopotency has been investigated by Western blot, immunufluorescence and ELISA. Luciferase reporter assay and Chromatin immunoprecipitation was used to investigate the regulation of the expression of Collagen type XV (ColXV) gene. Results: We identified ColXV as a new low $\mathrm{O}_{2}$ tension sensitive gene, and provided a novel mechanistic evidence that directly HIF-1 $\alpha$ (hypoxia-inducible factor- 1 alpha) mediates ColXV expression in response to hypoxia, since it was found specifically in vivo recruited at CoIXV promoter, in hypoxia-preconditioned hMSCs. This finding, together the evidence that also Runx2, VEGF and FGF-2 expression increased in hypoxia preconditioned hMSCs, is consistent with the possibility that increased ColXV expression in response to hypoxia is mediated by an early network that supports

E. Lambertini and L. Penolazzi contributed equally to this work.

\begin{tabular}{ll}
\hline Roberta Piva & Department of Biomedical and Specialty Surgical Sciences, University of Ferrara \\
& Via Fossato di Mortara 74, 44121 Ferrara (Italy) \\
& Tel. +39532974405, E-Mail piv@unife.it
\end{tabular}
\end{abstract}


Lambertini et al.: HIF- $1 \alpha$ and ColXV in Hypoxia-Preconditioned HMSCs

the osteogenic potential of the cells. Conclusion: These results add useful information to understand the role of a still little investigated collagen such as CoIXV, and identify CoIXV as a marker of successful hypoxia preconditioning. As a whole, our data give further evidence that hypoxia preconditioned hMSCs have greater osteopotency than normal hMSCs, and that the effects of hypoxic regulation of hMSCs activities should be considered before they are clinically applied.

(C) 2018 The Author(s)

Published by S. Karger AG, Basel

\section{Introduction}

The processes that take place during skeletal fracture and mechanisms underlying a possible spontaneous healing have only been partially understood [1,2]. By the use of appropriate experimental in vivo and in vitro models, it has been understood which cells, soluble factors and components of the extracellular matrix (ECM) have a key role, but the biological network and the metabolic adaptation is complex [3-6]. The knowledge in this field is certainly an essential prerequisite for developing potential cell-based regenerative therapies to obtain bone healing.

A major challenge is to accelerate bone repair/regeneration properly by restoring the functionality of damaged bone tissue, avoiding complications and maintaining the long-term reliability. This requires not only the identification of key molecules with regulatory function in the skeletal homeostasis, but also a concerted effort to try to standardize the experimental procedures and explain some conflicting results. The scenario is burdened by the fact that the ability of an organism to react to a bone insult depends on the type of damage and on many individual's inherent variables including biological factors present in the microenvironment of site of damage.

What happens during tissue regeneration at sites of bone damage is difficult to reproduce in in vitro experimental models, despite different approaches have been adopted to investigate both the cellular responsiveness to microenvironment perturbations and the susceptibility of certain genes to be modulated by specific cell culture conditions.

Oxygen $\left(\mathrm{O}_{2}\right)$ has been demonstrated to be a potent signaling molecule, and $\mathrm{O}_{2}$ tension is one of the crucial factors in the skeletal homeostasis that may be adequately monitored and changed in cell culture systems [7-12]. Vascular disruption during bone fracture creates a hypoxic environment within the developing callus [7]. Accordingly, the initial stages of repair at the fracture site occur in a hypoxic zone where a heterogeneous cell population including pluripotent mesenchymal stromal cells (MSCs), osteoblast precursors, mature osteoblasts and osteocytes is present $[7,13]$. Therefore, mimicking the natural microenvironment by lowering in vitro $\mathrm{O}_{2}$ tension could provide results closer to what happens in vivo. Moreover, hypoxic cultural environment could be of value for cell expansion/propagation before in vivo transplantation for bone tissue regeneration therapy $[8,9]$. This consideration is particularly critical for MSCs that, residing in bone marrow niches where the oxygen level is $1-2 \%$, require appropriate culture conditions just to preserve stem cell identity and to determine fate toward self-renewal or differentiation $[12,14,15]$. Some evidences suggest that a shortterm exposure to low $\mathrm{O}_{2}$ tension can play a critical role in directing stem cell fate towards a more robust osteogenic differentiation $[16,17]$. It is evident that different cellular pathways are influenced by the $\mathrm{O}_{2}$ tension, but many aspects remain to be explored. Oxygen signaling, although is not a core osteogenic pathway by itself, affect an array of osteogenic factors that, however, still remain to be investigated in detail. In order to shed light on the mechanisms supporting this phenomenon, the present study aimed to characterize the properties of hypoxia-preconditioned hMSCs, in terms of i. e. cellular ability to respond within a short time to variation of $\mathrm{O}_{2}$ tension, and ii. gene expression modulation. On the one hand, the rate and mode of response by the cells to in vitro treatments, such as low $\mathrm{O}_{2}$ tension, may be predictive of their ability to perceive the physiological microenvironment and the effectiveness of their potential use in vivo [18]. On the other, the identification of low $\mathrm{O}_{2}$ tension sensitive genes allows to recognize critical regulatory components of the osteogenic pathway, primarily 
involving HIF-1 $\alpha$ (hypoxia-inducible factor-1 alpha) [19]. As potential good candidate to analyze in this context we focused on non-fibrillar collagen (Col) XV, a chondroitin sulphate modified glycoprotein belonging to the multiplexin subfamily (multiple triple helix domains with interruptions), recently identified as a novel human osteoblast extracellular matrix (ECM) protein [20-22]. In particular, our previous evidence suggests that ColXV may act as an ECM organizer in the early-phases of the osteogenic process and that its expression in hMSCs is a prerequisite to promote the subsequent deposition of mineral matrix [23]. In this study, we further evaluate the role of ColXV testing the hypothesis that hypoxic environment may influence its expression in hMSCs.

\section{Materials and Methods}

\section{Isolation and growth of $h M S C S$}

Frozen hMSCs isolated from bone marrow aspirates of 12 healthy donors using Ficoll-Hypaque density gradient $(\mathrm{d}=1.077 \mathrm{~g} / \mathrm{ml})$, as previously described [23], were anonymously selected from the Laboratory repository. hMSCs were extensively characterized as previously reported [23, 24]. The cells were grown in $\alpha$-MEM medium supplemented with 15\% fetal bovine serum (FBS) (Euroclone S.p.A., Milan, Italy), penicillin-streptomycin $(100 \mathrm{U} / \mathrm{ml}-100 \mu \mathrm{g} / \mathrm{ml}$ ) (Sigma-Aldrich, St. Louis, MO, USA). At subconfluence, cells were trypsinized and expanded or used immediately for in vitro experiments.

\section{Cell culture under different oxygen tension}

hMSCs were plated at 20.000 cells $/ \mathrm{cm}^{2}$ and cultured in normoxic conditions at $95 \%$ air $\left(20 \% \mathrm{O}_{2}\right)-5 \%$ $\mathrm{CO}_{2}$ in a conventional incubator for $24 \mathrm{~h}$ at $37^{\circ} \mathrm{C}$, allowing the cells to attach. Plates were then divided into two groups and incubated under either normoxic or hypoxic conditions for $48 \mathrm{~h}$. For the hypoxic cultures, cells were incubated under full-time hypoxic preconditioning in the Xvivo System model X3 (BioSpherix Ltd., Parish, NY, USA) maintaining a hypoxic gas mixture composed of a $1.5 \% \mathrm{O}_{2}, 5 \% \mathrm{CO}_{2}$, and balanced $\mathrm{N}_{2}$ up to $48 \mathrm{~h}$ at $37^{\circ} \mathrm{C}$. The equipment consists of a modular set of closed incubator and closed hood, and allows high optimal solution for cell incubation and handling under hypoxic conditions, preventing the effect of brief interruption of culture condition that can compromise the outcome of the experiments.

\section{Scratch wound healing assay}

Scratch wounds were created in confluent hMSCs after $24 \mathrm{~h}$ of normoxia or hypoxia exposure by using a sterile $20 \mu \mathrm{l}$ pipette tip. After washing away suspended cells, cultures were refed with medium and cultured in the same experimental condition (normoxia and hypoxia) for further $24 \mathrm{~h}$. Cell migration into the wound space was estimated at 0 and $24 \mathrm{~h}$ after wounding with image analysis, using an inverted microscope (Nikon Corporation, Tokyo, Japan) equipped with a digital camera, and the NIH Image software. Wound closure was determined as the difference between wound width at 0 and $24 \mathrm{~h}$.

\section{Actin staining}

For analysis of F-actin organization, cells were fixed with $4 \%$ paraformaldehyde for 10 min. Subsequently, cells were washed with PBS 1X, permeabilized with $0.1 \%$ Triton X-100 for 15 min and stained with Phalloidin CruzFluor-633 conjugated (cat. no. sc-363796, Santa Cruz Biotechnology, Dallas, USA) for $30 \mathrm{~min}$ at room temperature. After washing with PBS 1X, the cells were mounted and observed using fluorescence microscopy (Nikon Eclipse 50i).

\section{Assessment of apoptosis}

Quantification of apoptotic cells were assessed with the Annexin V binding assay. Briefly, cells were collected and stained with Annexin V-FITC conjugated (Life Technologies, Carlsbad, CA, USA) (100 ng/ $\mathrm{ml}$ ) and propidium iodide (Sigma-Aldrich) $(10 \mu \mathrm{g} / \mathrm{ml})$ at room temperature in the dark for $15 \mathrm{~min}$. Flow cytometric analysis was performed with BD FACSCalibur (Becton-Dickinson Biosciences, San Jose, CA, USA), for each sample 20.000 cells were counted. Data analysis was performed with Kaluza Flow Analysis Software (Beckman Coulter, Brea, CA, USA). 


\section{Cellular Physiology Cell Physiol Biochem 2018;51:2237-2249 and Biochemistry Published \begin{tabular}{l|l} 
DOI: $10.1159 / 000495869$ & $\begin{array}{l}\text { (c) } 2018 \text { The Author(s). Published by S. Karger AG, Basel } \\
\text { www.karger.com/cpb }\end{array}$
\end{tabular}}

Lambertini et al.: HIF- $1 \alpha$ and ColXV in Hypoxia-Preconditioned HMSCS

Reactive oxygen species (ROS) measurement

The generation of intracellular ROS was examined by flow cytometry. $1 \times 10^{6}$ cells were incubated with $10 \mu \mathrm{M}$ dichlorodihydrofluorescein diacetate (DCFH-DA) (Thermo Fisher Scientific, Waltham, MA, USA) as substrate, in complete medium for $30 \mathrm{~min}$ at $37^{\circ} \mathrm{C}$ in dark to allow cellular incorporation. Cells were then washed, resuspended in PBS 1X, and kept on ice for an immediate detection by flow cytometry. ROS production was assessed based on the DCF fluorescence intensity from 15.000 cells by BD FACSCalibur (Becton-Dickinson). Data analysis was performed with Kaluza Flow Analysis Software (Beckman).

\section{CFU assay}

Colony-forming unit (CFU-F) assay was performed on hMSCs. Briefly, cells were plated in six-well plates at 250 cells $/ \mathrm{cm}^{2}$, incubated for $48 \mathrm{~h}$ in normoxic or hypoxic condition and then cultured over 7 days in normoxia. Thereafter, colonies were fixed with $100 \%$ cold methanol, stained with $1 \%$ crystal violet dye (Sigma-Aldrich) at room temperature, and washed twice. Colonies containing more than 30 nucleated cells were counted under Eclipse Ni-U microscope (Nikon Corporation).

\section{Western blot analysis}

Total cell extracts were prepared from cells exposed to normoxia or hypoxia condition as previously reported [25]. $20 \mu \mathrm{g}$ of each sample were electrophoresed through a 4-15\% SDS-polyacrylamide gradient gel. The proteins were then transferred onto an Immobilon-P PVDF membrane (Millipore, Billerica, MA). After blocking with TBS-0.1\% Tween-20 and 5\% nonfat dried milk (Sigma-Aldrich), the membrane was probed with the following antibodies: collagen type 15 (1:200; clone C-20), HIF-1 $\alpha$ (1:200; clone H1 $\alpha 67)$, Runx2 (1:500; clone M-70), Oct4 (1:500; clone C-10), Sox2 (1:500; clone E-4) (Santa Cruz Biotechnology), Sox9 (1:1000, \#AB5535, Merck Millipore, Germany), and VEGF (1:1000; clone VG-1, Abcam, Cambridge, UK). After washing with TBS- $0.1 \%$ Tween 20 , the membranes were incubated with the appropriate horseradish peroxidase conjugated secondary antibodies (Dako, Glostrup, Denmark). Immunocomplexes were detected using Immobilon Western Chemiluminescent HRP Substrate (Merck-Millipore). A mouse monoclonal anti$\beta$-actin antibody (Sigma-Aldrich) was used for normalization. Densitometric analysis was performed by ImageJ software (NIH, USA, public domain available at: http://rsb.info.nih.gov/nih-image/).

\section{Immunofluorescence analysis}

For detection of ColXV, Runx2 and Sox9, hMSCs were grown on glass cover slips, fixed with $4 \%$ paraformaldehyde (Sigma-Aldrich) for $10 \mathrm{~min}$, and permeabilized for $5 \mathrm{~min}$ at room temperature in $0.2 \%$ Triton X-100 in PBS 1X. Cells were then treated for 20 min with blocking solution (PBS 1X/1\% BSA/ $10 \%$ FBS), incubated over night at $4{ }^{\circ} \mathrm{C}$ with the anti-human collagen type15 (ColXV) (1:200, clone C-20), Runx2 (1:100, clone M-70) (Santa Cruz Biotechnologies) and Sox9 (1:100, \#AB5535, Merck Millipore) then stained for $45 \mathrm{~min}$ at room temperature with appropriate Alexa-488 fluorophore-conjugated secondary antibodies (1:200, Thermo Fisher). Nuclei were stained using DAPI solution $(0.5 \mu \mathrm{g} / \mathrm{ml}$, Sigma-Aldrich). The cells were mounted and observed using fluorescence microscopy (NikonEclipse 50i).

\section{Preparation of conditioned media and analysis of soluble factors}

Culture media from hMSCs incubated either in normoxia or hypoxia for $48 \mathrm{~h}$, was collected in $15 \mathrm{ml}$ tubes, centrifuged at $5.000 \mathrm{~g}$ at $4^{\circ} \mathrm{C}$ for $10 \mathrm{~min}$ to remove cell debris and stored at $-80^{\circ} \mathrm{C}$. The levels of FGF2 were detected by multiplex bead-based sandwich immunoassay kit (BioRad Laboratories Inc., Segrate, Italy), and ColXV was measured by the enzyme-linked immunosorbent assays (ELISA) using commercial Kit (FineTest, Wuhan, China), following the manifactures'indication. Each sample was analyzed in duplicate.

\section{Identification of HRE (hypoxia-response element) in the human COL15A1 gene promoter}

The prediction of hypoxia response elements (HRE) in the COL15A1 gene 5 ' flanking region spanning +56 to -539 , previously identified as core promoter [26], was performed using Patch 1.0 and AliBaba 2.1 public software. The analysis identified four canonical HREs, 5'-RCGTG-3'. 


\section{Cellular Physiology Cell Physiol Biochem 2018;51:2237-2249 \begin{tabular}{ll|l} 
DOl: 10.1159/000495869 & (0) 2018 The Author(s). Published by S. Karger AG, Basel \\
www.karger.com/cpb
\end{tabular}}

Lambertini et al.: HIF-1 $\alpha$ and ColXV in Hypoxia-Preconditioned HMSCS

Plasmid construction and luciferase reporter assay

A $593 \mathrm{bp}$ fragment containing the $5^{\prime}$-flanking region of the human COL15A1 gene $(-539$ to +56$)$ was generated by PCR using human genomic DNA of human HEK-293 cells as template. The PCR product was digested with MluI and HindIII (Promega, Madison, USA) and subsequently cloned into the promoterless pGL3 Basic vector containing a firefly luciferase cDNA (Promega), generating the pGL3ColXV-luc construct. For luciferase experiments, human cervical carcinoma HeLa cells were cultured in Dulbecco's modified Eagle's medium (DMEM) containing 10\% FBS (Euroclone) and transfected with 0.25 $\mu \mathrm{g}$ or $0.5 \mu \mathrm{g}$ of the reporter construct using Lipofectamine 2000 Reagent (Thermo Fisher), according to the manufacturer's instructions. 24 hours after transfection the medium was replaced and the cells were cultured, where required, in presence of $0.5 \mathrm{mM}$ of $\mathrm{CoCl}_{2}$ for another 24 hours. Cells were then washed once with PBS 1X and lysed in $120 \mu \mathrm{L}$ of $1 \mathrm{X}$ passive lysis buffer (Promega). The luciferase activity was measured using the Luciferase Assay System (Promega) in a GloMax 20/20 single tube Luminometer (Promega) and corrected for total protein content.

\section{Chromatin Immunoprecipitation Assay (ChIP)}

ChIP assays were performed as described previously $[27,28]$. Briefly, $7 \times 10^{6}$ cells were incubated for $48 \mathrm{~h}$ under hypoxia or normoxia. Crosslinking of DNA-bound protein was achieved by $10 \mathrm{~min}$ incubation of the cells in a $1 \%$ formaldehyde solution at room temperature. Next, cell lysates were sonicated, yielding an average DNA fragment size of 200-1000 bp. Immunoprecipitations were performed overnight $\left(4^{\circ} \mathrm{C}\right) \mathrm{using}$ $5 \mu \mathrm{g}$ ChIP-grade rabbit monoclonal anti-HIF-1 $\alpha$ antibody (cat. no. NB100-134 Novus Biologicals, CO, USA). Incubation with pre-immune rabbit IgG served as negative controls. The antibody-bound proteins were precipitated for $2 \mathrm{~h}$ at $4^{\circ} \mathrm{C}$ using $60 \mu \mathrm{l}$ of Protein A-conjugated agarose beads (Merck Millipore). After several washes in low-salt buffer, high-salt buffer, LiCl buffer, DNA was eluted from agarose beads with elution buffer and DNA samples were purified by PCR purification kit (Promega) following the kit instructions. The DNA was eluted in $50 \mu \mathrm{l}$ of RNase- and DNase-free water. Quantitative real-time PCR (40 cycles) was performed on a CFX 96 thermocycler (Bio-Rad, CA, USA) using iTaq Universal SYBR Green SuperMix (BioRad) and primer pairs spanned the 314 bp region $(-537 /-223)$ on the COL15A1 core promoter: Forward 5'-TCCACTCCTGGGCATTCAAGT-3', Reverse 5'-CTGCCTTATGTAACCTGCGA-3'. The Input fractions were used as the internal control. Quantification of HIF-1 $\alpha$-DNA binding was calculated as a fold enrichment using the $2^{(-\Delta \Delta C t)}$ method and normalized against the pre-immune IgG sample.

\section{Statistical analysis}

Data are expressed as the mean \pm standard deviation (SD) or as median with interquartile range. Comparison between two groups were assessed by non-parametric tests (Wilcoxon matched-pair signed rank test) because the data did not have a normal distribution. The statistical analysis was performed with GraphPad Prism 7.04 (La Jolla, CA, USA), data were considered significant when $\mathrm{p}<0.05$.

\section{Results}

\section{Culturing and characterization of hMSCs in hypoxia}

Bone marrow derived hMSCs were obtained from 12 donors. Considering that, in vivo, these cells reside in the niche areas of bone marrow where the standard oxygen level is 1-2\% [29], short-term hypoxic exposure was performed at $1.5 \% \mathrm{O}_{2}$ and compared with standard cell culture condition (normoxia). A first series of experiments, as shown below, demonstrated the beneficial effects of hypoxia preconditioning.

Firstly, the cells were tested for their migratory capabilities that is one of the inherent traits of all MSCs [30]. As shown in Fig. 1, after $48 \mathrm{~h}$ of culture a significant increase of hMSC migration in hypoxic condition was observed. In addition, hypoxia preconditioning did not significantly affect the actin cytoskeletal organization, reactive oxygen species (ROS) production and cell viability, as demonstrated by the TRITC-Phalloidin binding (Fig. 2A), DCF-DA assay (Fig. 2B) and Annexin-propidium iodide staining (Fig. 2C), respectively. 
These evidences suggest that the exposure of hMSCs to hypoxic priming didn't activate in the first 48 hours those undesired/ adverse effects such as ROS accumulation which can lead to apoptosis, resulting in lethal cell injuries.

\section{Detection and confirmation of cellular hypoxia preconditioning}

To confirm that the hMSCs metabolically responded to hypoxia preconditioning, we assessed whether the cells exposed to $1.5 \% \mathrm{O}_{2}$ activated the HIF- $1 \alpha$, a central regulator of the cellular response to hypoxia ubiquitously expressed in mammalian cells [31]. Western blot analysis revealed a significant increase of HIF$1 \alpha$ protein in the hypoxic hMSCs respect to the normoxic control hMSCs (Fig. 3A). Consistently, the expression of vascular endothelial growth factor (VEGF), a primary transcriptional target of HIF-1 $\alpha$ [32], significantly increased in the hypoxic samples (Fig. 3A), as well as the secretion of fibroblast growth factor 2 (FGF-2) [33] whose induction required HIF$1 \alpha$ (Fig. 3B).

Stemness properties after hypoxia preconditioning have been also evaluated in terms of clonogenicity and expression of stemness-related genes such as pluripotent factors OCT-4 and SOX-2 which are transcription factors essential for self-renewal and survival of MSCs [34, 35]. As shown in Fig. 3C, the cells did not show significant change of OCT4 and SOX-2 protein expression level suggesting that hypoxiapreconditioned hMSCs retained a multipotency similar to those cultured in normoxia. Likewise, the CFU-F assay, useful to define the number of progenitor cells

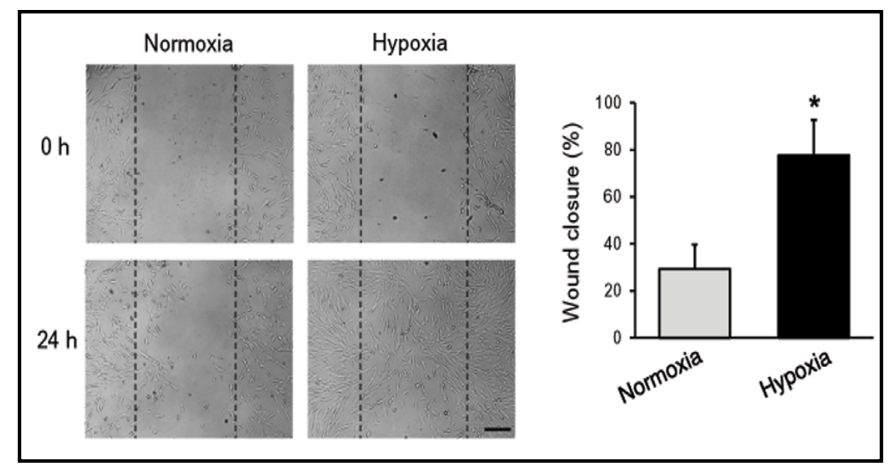

Fig. 1. Effect of hypoxia preconditioning on the wound closure ability of hMSCs. Confluent hMSCs were maintained for $24 \mathrm{~h}$ in normoxia or hypoxia $\left(1.5 \% \mathrm{O}_{2}\right)$ prior to wounding. Scratch wounds were created by using a sterile $20 \mu$ pipette tip $(0 \mathrm{~h})$ and observed over the indicated time periods, 0 and 24 hours. A representative wounds scratch both in normoxia and hypoxia is shown in the pictures (magnification, 4X). Scale bar $=50 \mu \mathrm{m}$. The percentage of wound closure was quantified as the difference between wound width at 0 and $24 \mathrm{~h}$, in three separate experiments. ${ }^{*} \mathrm{p}<0.05$.

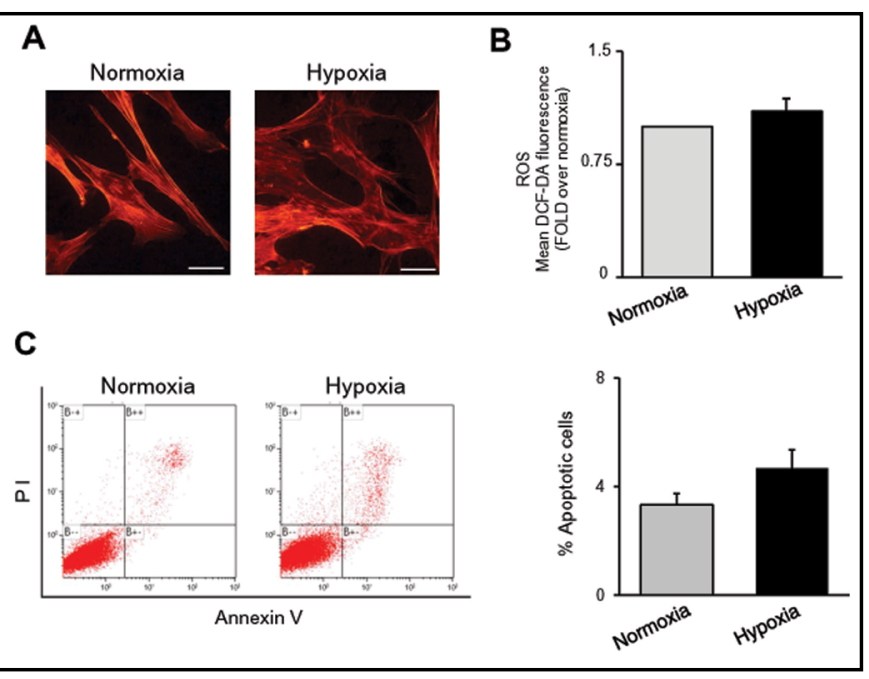

Fig. 2. Effect of hypoxia preconditioning on actin cytoskeletal organization, ROS production and cell viability of hMSCs. (A) The distribution of F-actin filaments was revealed by Phalloidin CruzFluor-633 conjugated staining and detected by fluorescence microscope at $40 \mathrm{X}$ magnification, Scale bar $=20 \mu \mathrm{m}$. (B) Intracellular levels of ROS was measured by DCF-DA assay; data are expressed as mean \pm SD of three independent experiments each one performed in triplicate. (C) hMSCs were harvested and stained with Annexin V-propidium iodide (PI) before analyzed by flow cytometry. Representative Annexin V-PI plots both in normoxia and hypoxia are shown. The histogram represents the percentage of apoptotic cells (ratio of Annexin V-positive cells/ total cells). Data are expressed as mean \pm S.D. of three independent experiments. 


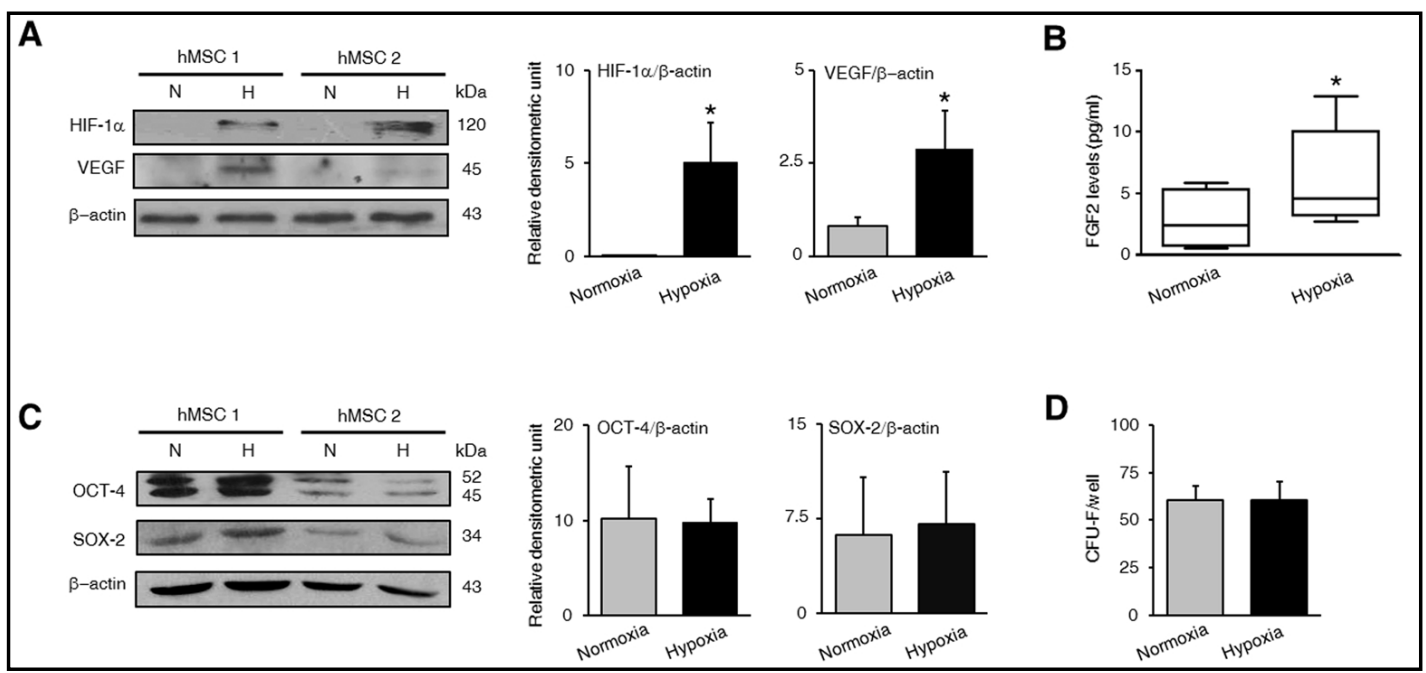

Fig. 3. Hypoxia preconditioning induced the expression of HIF-1 $\alpha$ protein and its targets in hMSCs. (A) Expression of HIF- $1 \alpha$ and VEGF were evaluated by Western blot in hMSCs exposed to hypoxia (H) or normoxia (N). Representative Western blots are reported with densitometric analysis of all samples analyzed $(n=6)$. Data are expressed as mean \pm SD of HIF- $1 \alpha / \beta$-actin or VEGF $/ \beta$-actin ratio, of four independent experiments. ${ }^{*} \mathrm{p}<0.05$ versus normoxia. (B) Conditioned media were collected from hMSCs and FGF2 protein level was determined by ELISA. Data are expressed as median with interquartile range of four independent experiments in duplicate. ${ }^{*} \mathrm{p}<0.05$, compared with normoxia. (C) Expression of OCT-4 and SOX-2 were evaluated by Western blot in hMSCs exposed to hypoxia $(\mathrm{H})$ or normoxia $(\mathrm{N})$. Representative Western blots are reported with densitometric analysis of all samples analyzed $(n=4)$. Data are expressed as mean \pm SD of OCT-4/ $\beta$-actin or SOX-2/ $\beta$-actin ratio, of four independent experiments. (D) The effect of hypoxia preconditioning on colony forming ability of hMSCs was determined by CFU-F assay. Cells were plated in six-well plates at 250 cells $/ \mathrm{cm}^{2}$, incubated for $48 \mathrm{~h}$ in normoxic or hypoxic condition and then cultured over 7 days. The plates were stained with cristal violet and the colonies (CFU-F) were manually counted. Data are expressed as the average number of colonies per well \pm SD of three independent experiments.

and to predict the performance of any cell based therapeutic [36], demonstrated that shortterm hypoxia exposure did not affect colony forming ability of the cells (Fig. 3D).

\section{ColXV expression in hypoxia-preconditioned hMSCs}

In order to investigate if hypoxia preconditioning has beneficial effects in making cells more prone to osteo-differentiation, the expression of ColXV, previously identified as predictive marker for selecting hMSCs with high osteo-differentiation potential [23], has been assessed at different levels. As reported in Fig. 4A, Western blot analysis showed that ColXV protein levels, which were detectable under normoxia, greatly increased in hypoxia-preconditioned hMSCs. These data were confirmed by immunofluorescent analysis carried out on fixed cells (Fig. 4A). As expected from the lack of ascorbate in the culture medium [37], hMSCs secreted only low levels of ColXV both in normoxia and hypoxia as revealed by ELISA (Fig. 4A). To strengthen the hypothesis that hypoxia-mediated increase of ColXV positively affects the osteogenic potential of the cells, the expression levels of Runx2, the master regulator required for osteoblast cell-fate determination, and Sox9, the key regulator for chondrogenic lineage determination, were assessed (Fig. 4B). It is known that the balance between Runx 2 and Sox 9 activity is critical for the process of cartilage and bone development, and that an high ratio of Runx2/Sox9 gene expression is associated with the successfull osteogenic differentiation of hMSCs osteo-chondroprogenitors [38]. Interestingly and according to our hypothesis, Western blot and immunofluorescent analysis showed that these two transcription factors are co-expressed in the hMSCs, and that hypoxia preconditioning is effective in increasing Runx2, and in decreasing Sox9 expression levels (Fig. 4B). 
Fig. 4. Hypoxia preconditioning induced the expression of ColXV protein in hMSCs. (A) Expression of ColXV was evaluated by Western blot and immunofluorescence in hMSCs exposed to hypoxia $(\mathrm{H})$ or normoxia $(\mathrm{N})$. Representative Western blots are reported with densitometric analysis of all samples analyzed. Data are expressed as mean \pm SD of $\mathrm{ColXV} / \beta$-actin ratio, of six independent experiments. Each experiment was repeated in duplicate. A representative immunofluorescence staining of hMSC for ColXV (green) is showed. The nuclei counterstained are blue (merged image). Conditioned media were collected from hMSCs and ColXV protein level was determined by ELISA. Data are expressed as median with interquartile range of four independent experiments in duplicate. (B) Runx2 and Sox9 expression level was evaluated by Western blot and immunofluorescence in hMSCs

exposed to hypoxia $(\mathrm{H})$ or normoxia $(\mathrm{N})$. Representative Western blots are reported with densitometric analysis of all samples analyzed. Data are expressed as mean \pm SD of Runx $2 / \beta$-actin or Sox $9 / \beta$-actin ratio, of six independent experiments. Each experiment was repeated in duplicate. A representative immunofluorescence staining of hMSCs for Runx2 or Sox9 (green) is showed. The nuclei were counterstained with DAPI (blue). Images shown are representative of four independent experiments. Magnification, 40X; scale bars $=20 \mu \mathrm{m} .{ }^{*} \mathrm{p}<0.05$, compared with normoxia.

Fig. 5. Regulation of the COL15A1 promoter activity under hypoxia. Transcriptional activity of COL15A1 promoter under hypoxia was evaluated by luciferase assay using the plasmidic construct pGL3-ColXVLuc containing the minimal core promoter of ColXV gene $(-539 /+56)$ which is represented at the top with the positioning of HIF- $1 \alpha$ putative responsive elements (HRE) as ovals. HeLa cells were transfected with 0.25 or $0.5 \mu \mathrm{g}$ of pGL3-ColXV-Luc or promoterless pGL3-Basic vector, in the presence $(+)$ or in absence $(-)$ of the hypoxia mimicking agent $\mathrm{CoCl}_{2}$ for

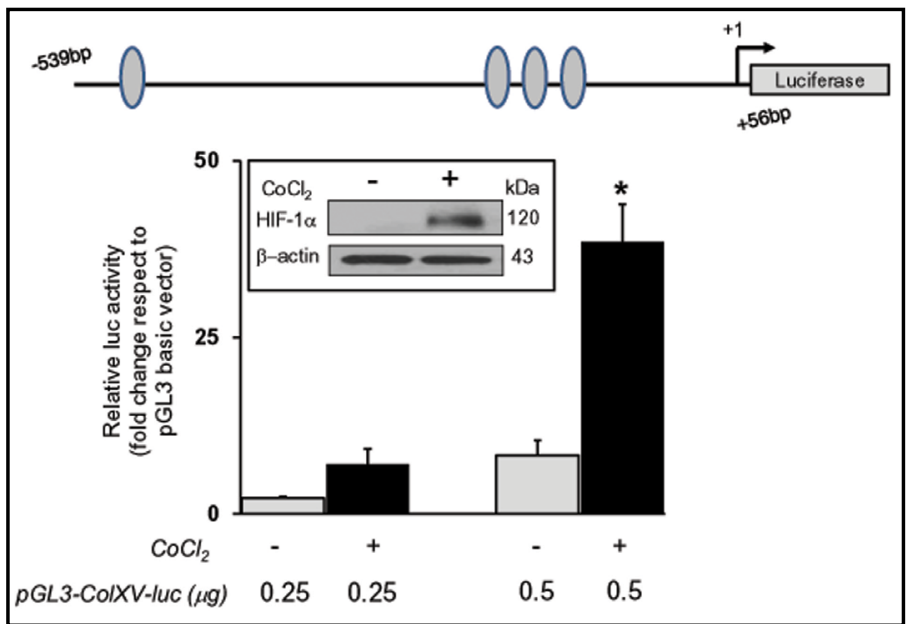

24 hours. The transfection efficiency was normalized by measuring the total protein in the cell lysates. For fold change, the luciferase output was normalized against the promoterless pGL3-Basic vector, arbitrarily defined as 1 . Results are expressed as mean + SD of three independent experiments. Each experiment was repeated in triplicate. ${ }^{*} \mathrm{p}<0.05$. The efficacy of $\mathrm{CoCl}_{2}$ in inducing HIF- $1 \alpha$ protein was monitored by Western blot analysis and reported in the inset.
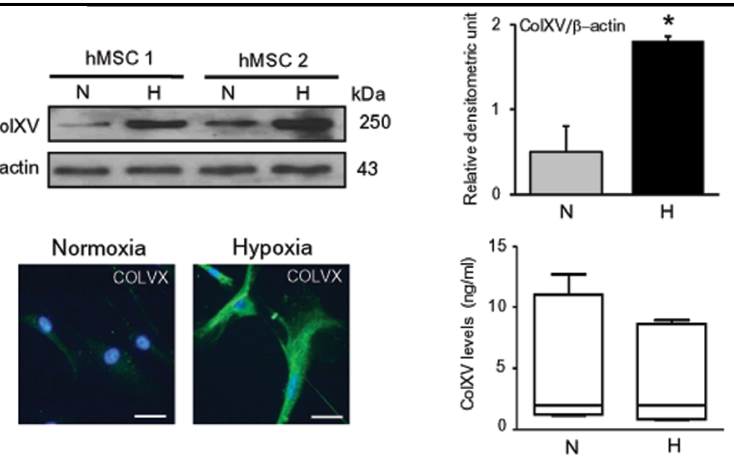

B
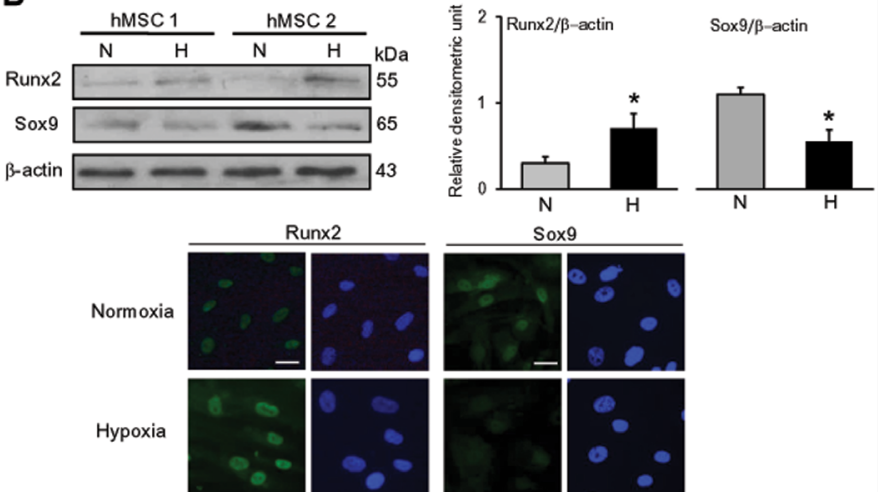

Hypoxia
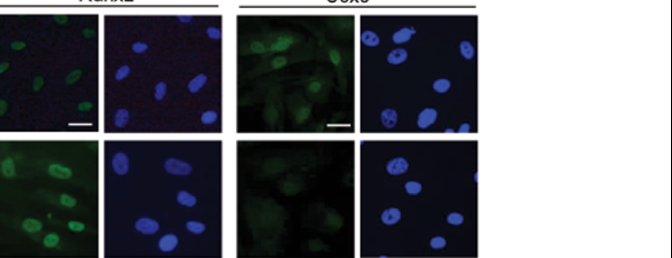

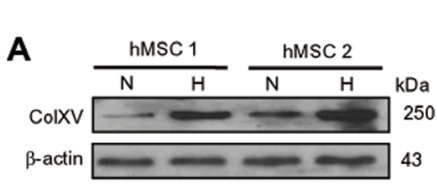


ColXV is a direct target of $H I F-1 \alpha$

Relatively little is known about the regulation of the expression of COLXV gene. By using Patch 1.0 and AliBaba 2.1 public software for transcription binding sites search, we identified four potential HIF-1 $\alpha$ binding sites (HREs) in the ColXV gene regulatory region. To determine whether HIF$1 \alpha$ activity plays a role in ColXV transcriptional activation, HeLa cells were transfected with the pGL3-ColXV-luc reporter construct containing the human ColXV core promoter [26]. As shown in Fig. 5, in the presence of the hypoxia mimicking agent $\mathrm{CoCl}_{2}$ the expression of HIF-1 $\alpha$ significantly increased. Likewise the activity of ColXV promoter

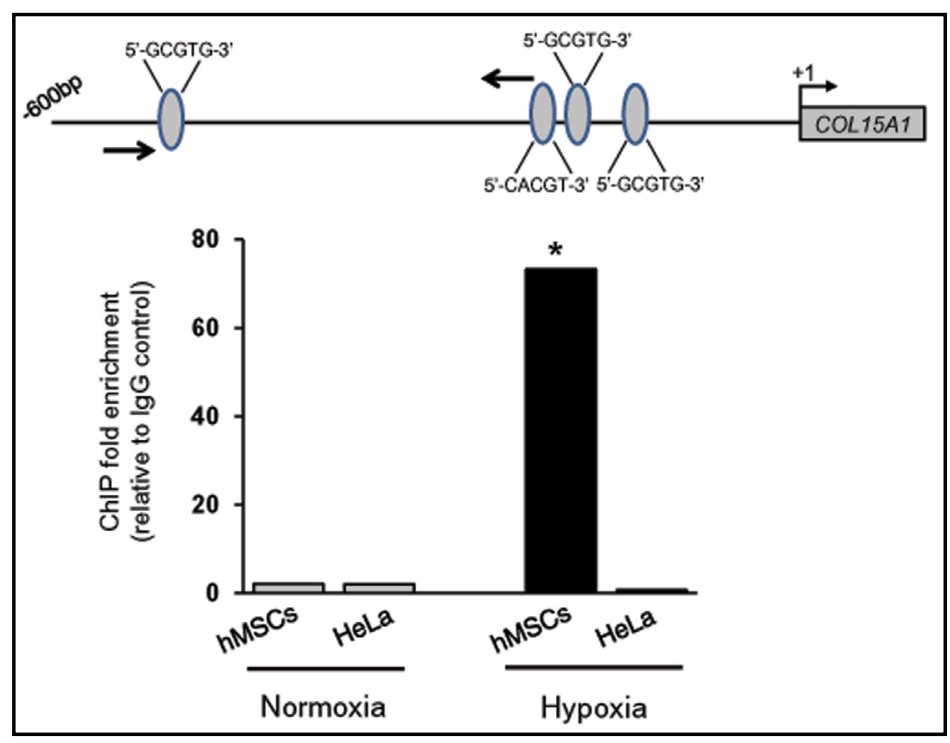

Fig. 6. Hypoxia-inducible factor-1 (HIF-1 $\alpha$ ) is in vivo recruited to the COL15A1 promoter in hMSCs. The positioning and sequences (5'-RCGTG-3') of HIF-1 $\alpha$ potential binding sites within the COL15A1 core promoter together with the position of the specific primers used for qPCR amplifications of anti-HIF- $1 \alpha$ immunoprecipitated chromatin are reported. The graph shows the results of ChIP-qPCR analysis performed on DNA templates obtained from hMSCs and HeLa cells exposed to hypoxia or normoxia. Results of qPCR were analyzed by the $2^{(-\Delta \Delta \mathrm{Ct})}$ method after normalization to the IgG negative control and data expressed as mean \pm SD of four independent experiments. ${ }^{*} \mathrm{p}<0.05$. was positively affected by $\mathrm{CoCl}_{2}$ in a dose-dependent manner.

The possibility that ColXV is a direct transcriptional target of HIF-1 $\alpha$ was examined by ChIP assay in hMSCs, performing for the first time an "in vivo" HRE occupancy analysis. As reported in Fig. 6, HIF-1 $\alpha$ was specifically recruited at ColXV promoter in hypoxiapreconditioned hMSCs.

\section{Discussion}

Culture conditions and cellular signals that can influence the potential therapeutic outcomes of hMSCs are of great interest. For this reason, the ability of hMSCs to respond to a potent signaling molecule such as oxygen needs to be studied, also in view of optimizing stem cell-based therapies in the context of bone regenerative medicine and tissue engineering [39].

Most studies involving progenitor/stem cells are conventionally performed under ambient $\mathrm{O}_{2}$ tension, without considering the hypoxic physiological niche in which most stem cells normally grow or reside. In the recent years the impact of hypoxic culture systems on the behavior of hMSCs from different sources has been investigated, and it has been demonstrated that hypoxia preconditioning increases the therapeutic potential of MSC in the treatment of ischemic diseases [40-42], traumatic brain injury [43], and in liver regeneration [44].

Although the role of hypoxia in positively conditioning hMSC multipotency, longevity, expansion, secretion and migration ability is widely accepted $[8,15,29]$, the effects of a low oxygen microenvironment on hMSC osteogenic potential are often contradictory [16, 45- 


\section{Cellular Physiology Cell Physiol Biochem 2018;51:2237-2249

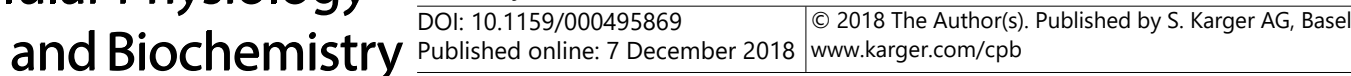

Lambertini et al.: HIF-1 $\alpha$ and ColXV in Hypoxia-Preconditioned HMSCS

48]. In fact, both the up- or down-regulation of proliferation or differentiation of hMSCs by hypoxic culture conditions have been described. The discrepancies reported in literature are likely due to the different protocols, culture media composition, oxygen tension applied, and timing of hypoxia treatment, as well as the heterogeneity of donors. Another important aspect to consider is that cellular adaptation to oxygen tension is a quick event, and hypoxia responses are primarily mediated by signaling pathways involving the hypoxia-inducible factor HIF- $1 \alpha$ which is only transiently maintained under hypoxic culture conditions [49]. Consequently, the limited stability of HIF- $1 \alpha$ could mask its effective role in hMSCs during a prolonged biological process, such as osteogenic terminal differentiation. Moreover, even if the interplay between glucocorticoid and HIF-1 $\alpha$ in hypoxic areas remains unclear, many evidences demonstrated that dexamethasone reduces protein level of HIF- $1 \alpha$ as well as its activity affecting transcription of HIF- $1 \alpha$ target genes [50,51]. Therefore, we cannot exclude that long-term hypoxic treatment in vitro can lead to results that are difficult to explain when hMSCs are induced to differentiate toward the osteogenic lineage by the conventional dexamethasone-added osteogenic medium. These observations lead us to formulate the hypothesis that the first hours of exposure to the hypoxic microenvironment may play a critical role in producing the benefit of hypoxic conditioning, as found in many different experimental models, and that the precise mechanism through which low oxygen tension affects the cells should be investigated at the early stage.

Therefore, we focused our attention on what happens during the 48 hours of hypoxia preconditioning without adding osteogenic medium, by investigating the expression modulation of critical genes which could be good candidates as markers of increased osteopotency.

In the present paper, we described the efficient production of hypoxia preconditioned hMSCs by using the X3 Hypoxia Hood and Culture Combo - Xvivo System device, able to maintain a stable oxygen tension during the entire period of culture, observation and cellular manipulation. In these conditions the cells showed a significant increase of migration without significant signs of apoptosis, cytoskeleton disorganization or ROS accumulation.

We recently demonstrated that a chondroitin sulphate modified glycoprotein, the ColXV $[20,21]$ is a critical regulatory component of the osteogenic pathway and that its expression in hMSCs is a prerequisite to promote the subsequent deposition of mineral matrix [23]. For the first time we correlated the increase of HIF-1 $\alpha$ expression after hypoxia preconditioning with the increase of ColXV. We identified ColXV as low oxygen tension sensitive gene, providing a novel mechanistic evidence that HIF- $1 \alpha$ mediates ColXV expression in response to hypoxia. Importantly, this finding, together with the evidence that also VEGF and Runx2 expression increased, as well as Runx2/Sox9 gene expression ratio, in hypoxia preconditioned hMSCs, is consistent with the hypothesis that increased ColXV expression in response to hypoxia is mediated by a network of early regulators that support the osteogenic potential of the cells. Moreover, these data help to understand the role of collagens, identifying ColXV not only as a good marker of increased osteopotency, but also as a new marker of successful hypoxia preconditioning.

\section{Conclusion}

In this perspective it is important to emphasize that: $i$. the ability of cells to respond within a short time to in vitro treatments should be predictive of their ability to perceive the physiological microenvironment and the effectiveness of their in vivo potential use; and ii. identifying good markers that give a measure of cell responsiveness allows us to both have important information on the adequacy of the cells we are using, and speculate the importance of a specific pre-treatment as step before clinical cells transplantation.

In conclusions, our data give further evidence that hypoxia-preconditioned hMSCs have greater osteopotency than normal hMSCs, and that the effects of hypoxic regulation of hMSCs activities should be an important parameter to consider before they are clinically applied. 


\section{Cellular Physiology Cell Physiol Biochem 2018;51:2237-2249 and Biochemistry Published \begin{tabular}{l|l} 
DOI: $10.1159 / 000495869$ & $\begin{array}{l}\text { (c) } 2018 \text { The Author(s). Published by S. Karger AG, Basel } \\
\text { www.karger.com/cpb }\end{array}$
\end{tabular}}

Lambertini et al.: HIF- $1 \alpha$ and ColXV in Hypoxia-Preconditioned HMSCs

\section{Acknowledgements}

We thank Dr. Paolo Ferraresi for technical assistance. This study was supported by a grant from University of Ferrara - FIR 2017, "Strumenti per la Ricerca di Ateneo 2015" and Funds "5 per mille and Ricerca corrente" Istituto Ortopedico Rizzoli.

\section{Disclosure Statement}

The authors declare no conflict of interest.

\section{References}

1 Schindeler A, McDonald MM, Bokko P, Little DG: Bone remodeling during fracture repair: the cellular picture. Semin Cell Dev Biol 2008;19:459-466.

-2 Ai-Aql ZS, Alagl AS, Graves DT, Gerstenfeld LC, Einhorn TA: Molecular mechanisms controlling bone formation during fracture healing and distraction osteogenesis. J Dent Res 2008;87:107-118.

3 Marsell R, Einhorn TA: The biology of fracture healing. Injury 2011;42:551-555.

4 Majidinia M, Sadeghpour A, Yousefi B: The roles of signaling pathways in bone repair and regeneration. J Cell Physiol 2018;233:2937-2948.

5 Loeffler J, Duda GN, Sass FA, Dienelt A: The metabolic microenvironment steers bone tissue regeneration. Trends Endocrinol Metab 2018;29:99-110.

6 Watt FM, Huck WT: Role of the extracellular matrix in regulating stem cell fate. Nat Rev Mol Cell Biol 2013;14:467-473.

7 Maes C, Carmeliet G, Schipani E: Hypoxia-driven pathways in bone development, regeneration and disease. Nat Rev Rheumatol 2012;8:358-366.

-8 Das R, Jahr H, van Osch GJ, Farrell E: The role of hypoxia in bone marrow-derived mesenchymal stem cells: considerations for regenerative medicine approaches. Tissue Eng Part B Rev 2010;16:159-168.

-9 Ren H, Cao Y, Zhao Q Li J, Zhou C, Liao L, Jia M, Zhao Q, Cai H, Han ZC, Yang R, Chen G, Zhao RC: Proliferation and differentiation of bone marrow stromal cells under hypoxic conditions. Biochem Biophys Res Commun 2006;347:12-21.

10 Jagannathan L, Cuddapah S, Costa M: Oxidative stress under ambient and physiological oxygen tension in tissue culture. Curr Pharmacol Rep 2016;2:64-72.

11 Werle SB, Chagastelles P, Pranke P, Casagrande L: The effects of hypoxia on in vitro culture of dental-derived stem cells. Arch Oral Biol 2016;68:13-20.

12 Ahmed NE, Murakami M, Kaneko S, Nakashima M: The effects of hypoxia on the stemness properties of human dental pulp stem cells (DPSCs). Sci Rep 2016;6:35476.

13 Miclau KR, Brazina SA, Bahney CS, Hankenson KD, Hunt TK, Marcucio RS, Miclau T: Stimulating fracture healing in ischemic environments: does oxygen direct stem cell fate during fracture healing? Front Cell Dev Biol 2017;5:45.

14 Sotiropoulou PA, Perez SA, Salagianni M, Baxevanis CN, Papamichail M: Characterization of the optimal culture conditions for clinical scale production of human mesenchymal stem cells. Stem Cells 2006;24:462471.

15 Kim DS, Ko YJ, Lee MW, Park HJ, Park YJ, Kim DI, Sung KW, Koo HH, Yoo KH: Effect of low oxygen tension on the biological characteristics of human bone marrow mesenchymal stem cells. Cell Stress Chaperones 2016;21:1089-1099.

16 Volkmer E, Kallukalam BC, Maertz J, Otto S, Drosse I, Polzer H, Bocker W, Stengele M, Docheva D, Mutschler W, Schieker M: Hypoxic preconditioning of human mesenchymal stem cells overcomes hypoxia-induced inhibition of osteogenic differentiation. Tissue Eng Part A 2010;16:153-164.

17 Fan L, Zhang C, Yu Z, Shi Z, Dang X, Wang K: Transplantation of hypoxia preconditioned bone marrow mesenchymal stem cells enhances angiogenesis and osteogenesis in rabbit femoral head osteonecrosis. Bone 2015;81:544-553. 


\section{Cellular Physiology Cell Physiol Biochem 2018;51:2237-2249 \begin{tabular}{l|l|l} 
and Biochemistry Published onlıne: / December 2018 & $\begin{array}{l}\text { (c) } 2018 \text { The Author(s). Published by S. Karger AG, Basel } \\
\text { www.karger.com/cpb }\end{array}$ \\
\hline
\end{tabular}}

18 Greco SG, Rameshwar P: Microenvironmental considerations in the application of human mesenchymal stem cells in regenerative therapies. Biologics 2008;2:699-705.

19 Johnson RW, Schipani E, Giaccia AJ: HIF targets in bone remodeling and metastatic disease. Pharmacol Ther 2015;150:169-177.

20 Amenta PS, Scivoletti NA, Newman MD, Sciancalepore JP, Li D, Myers JC: Proteoglycan-collagen XV in human tissues is seen linking banded collagen fibers subjacent to the basement membrane. J Histochem Cytochem 2005;53:165-176.

21 Lisignoli G, Codeluppi K, Todoerti K, Manferdini C, Piacentini A, Zini N, Grassi F, Cattini L, Piva R, Rizzoli V, Facchini A, Giuliani N, Neri A: Gene array profile identifies collagen type XV as a novel human osteoblastsecreted matrix protein. J Cell Physiol 2009;220:401-409.

22 Gabusi E, Manferdini C, Grassi F, Piacentini A, Cattini L, Filardo G, Lambertini E, Piva R, Zini N, Facchini A, Lisignoli G: Extracellular calcium chronically induced human osteoblasts effects: specific modulation of osteocalcin and collagen type XV. J Cell Physiol 2012;227:3151-3161.

23 Lisignoli G, Lambertini E, Manferdini C, Gabusi E, Penolazzi L, Paolella F, Angelozzi M, Casagranda V, Piva R: Collagen type XV and the 'osteogenic status'. J Cell Mol Med 2017;21:2236-2244.

24 Lisignoli G, Manferdini C, Lambertini E, Zini N, Angelozzi M, Gabusi E, Gambari L, Penolazzi L, Lolli A, Facchini A, Piva R: Chondrogenic potential of Slug-depleted human mesenchymal stem cells. Tissue Eng Part A 2014;20:2795-2805.

25 Lolli A, Lambertini E, Penolazzi L, Angelozzi M, Morganti C, Franceschetti T, Pelucchi S, Gambari R, Piva R: Pro-chondrogenic effect of miR-221 and slug depletion in human MSCs. Stem Cell Rev 2014;10:841-855.

26 Hägg PM, Muona A, Liétard J, Kivirikko S, Pihlajaniemi T: Complete exon-intron organization of the human gene for the alpha1 chain of type XV collagen (COL15A1) and comparison with the homologous COL18A1 gene. J Biol Chem 1998; 273:17824-17831.

27 Lambertini E, Franceschetti T, Torreggiani E, Penolazzi L, Pastore A, Pelucchi S, Gambari R, Piva R: SLUG: a new target of lymphoid enhancer factor-1 in human osteoblasts. BMC Mol Biol 2010;11:13.

28 Lambertini E, Penolazzi L, Angelozzi M, Grassi F, Gambari L, Lisignoli G, De Bonis P, Cavallo M, Piva R: The expression of cystathionine gamma-lyase is regulated by estrogen receptor alpha in human osteoblasts. Oncotarget 2017;8:101686-101696.

29 Mohyeldin A1, Garzón-Muvdi T, Quiñones-Hinojosa A: Oxygen in stem cell biology: a critical component of the stem cell niche. Cell Stem Cell 2010;7:150-161.

-30 Chamberlain G, Fox J, Ashton B, Middleton J: Concise review: mesenchymal stem cells: their phenotype, differentiation capacity, immunological features, and potential for homing. Stem Cells 2007;25:2739-2749.

-31 Hu CJ, Wang LY, Chodosh LA, Keith B, Simon MC: Differential roles of Hypoxia-Inducible Factor $1 \alpha($ HIF-1 $\alpha)$ and HIF-2 $\alpha$ in hypoxic gene regulation. Mol Cell Biol 2003;23:9361-9374.

-32 Komatsu DE1, Hadjiargyrou M: Activation of the transcription factor HIF-1 and its target genes, VEGF, HO1, iNOS, during fracture repair. Bone 2004;34:680-688.

-33 Fábián Z, Ramadurai S, Shaw G, Nasheuer HP, Kolch W, Taylor C, Barry F: Basic fibroblast growth factor modifies the hypoxic response of human bone marrow stromal cells by ERK-mediated enhancement of HIF-1 $\alpha$ activity. Stem Cell Res 2014;12:646-658.

-34 Greco SJ, Liu K, Rameshwar P: Functional similarities among genes regulated by OCT4 in human mesenchymal and embryonic stem cells. Stem Cells 2007;25:3143-3154.

-35 Yoon D, Kim Y, Jung H, Paik S, Lee J: Importance of Sox2 in maintenance of cell proliferation and multipotency of mesenchymal stem cells in low-density culture. Cell Prolif 2011;44:428-440.

-36 Castro-Malaspina H, Gay RE, Resnick G, Kapoor N, Meyers P, Chiarieri D, McKenzie S, Broxmeyer HE, Moore MA: Characterization of human bone marrow fibroblast colony-forming cells (CFU-F) and their progeny. Blood 1980;56:289-301.

37 Franceschi RT, Iyer BS, Cui Y: Effects of ascorbic acid on collagen matrix formation and osteoblast differentiation in murine MC3T3-E1 cells. J Bone Miner Res 1994;9:843-854.

38 Loebel C, Czekanska EM, Bruderer M, Salzmann G, Alini M, Stoddart MJ: In vitro osteogenic potential of human mesenchymal stem cells is predicted by Runx2/Sox9 ratio. Tissue Eng Part A 2015;21:115-123.

39 Bianco P, Cao X, Frenette PS, Mao JJ, Robey PG, Simmons PJ, Wang CY: The meaning, the sense and the significance: translating the science of mesenchymal stem cells into medicine. Nat Med 2013;19:35-42. 


\section{Cellular Physiology Cell Physiol Biochem 2018:51:2237-2249

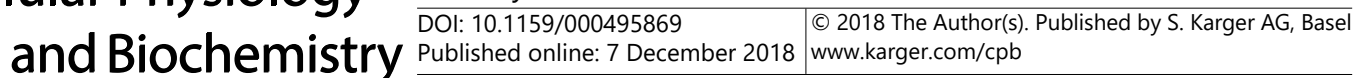

Lambertini et al.: HIF-1 $\alpha$ and ColXV in Hypoxia-Preconditioned HMSCS

40 Hu X, Yu SP, Fraser JL, Lu Z, Ogle ME, Wang JA, Wei L: Transplantation of hypoxia-preconditioned mesenchymal stem cells improves infarcted heart function via enhanced survival of implanted cells and angiogenesis. J Thorac Cardiovasc Surg 2008;135:799-808.

41 Yan Z, Shen D, Liao J, Zhang Y, Chen Y, Shi G, Gao F: Hypoxia suppresses TGF-B1-induced cardiac myocyte myofibroblast transformation by inhibiting Smad2/3 and Rhoa signaling pathways. Cell Physiol Biochem 2018;45:250-257.

42 Rosová I, Dao M, Capoccia B, Link D, Nolta JA: Hypoxic preconditioning results in increased motility and improved therapeutic potential of human mesenchymal stem cells. Stem Cells 2008;26:2173-2182.

43 Chang CP, Chio CC, Cheong CU, Chao CM, Cheng BC, Lin MT: Hypoxic preconditioning enhances the therapeutic potential of the secretome from cultured human mesenchymal stem cells in experimental traumatic brain injury. Clin Sci 2013;124:165-176.

44 Yu J, Yin S, Zhang W, Gao F, Liu Y, Chen Z, Zhang M, He J, Zheng S: Hypoxia preconditioned bone marrow mesenchymal stem cells promote liver regeneration in a rat massive hepatectomy model. Stem Cell Res Ther 2013;4:83.

45 Fehrer C, Brunauer R, Laschober G, Unterluggauer H, Reitinger S, Kloss F, Gülly C, Gassner R, Lepperdinger G: Reduced oxygen tension attenuates differentiation capacity of human mesenchymal stem cells and prolongs their lifespan. Aging Cell 2007;6:745-757.

46 Ciapetti G, Granchi D, Fotia C, Savarino L, Dallari D, Del Piccolo N, Donati DM, Baldini N: Effects of hypoxia on osteogenic differentiation of mesenchymal stromal cells used as a cell therapy for avascular necrosis of the femoral head. Cytotherapy 2016;18:1087-1099.

47 Youssef A, Han VKM: Regulation of osteogenic differentiation of placental-derived mesenchymal stem cells by insulin-like growth factors and low oxygen tension. Stem Cells Int 2017; 2017:4576327.

-48 Hsu SH, Chen CT, Wei YH: Inhibitory effects of hypoxia on metabolic switch and osteogenic differentiation of human mesenchymal stem cells. Stem Cells 2013;31:2779-2788.

-49 Park IH, Kim KH, Choi HK, Shim JS, Whang SY, Hahn SJ, Kwon OJ, Oh IH: Constitutive stabilization of hypoxia-inducible factor alpha selectively promotes the self-renewal of mesenchymal progenitors and maintains mesenchymal stromal cells in an undifferentiated state. Exp Mol Med 2013;45:e44.

50 Wagner AE, Huck G, Stiehl DP, Jelkmann W, Hellwig-Bürgel T: Dexamethasone impairs hypoxia-inducible factor-1 function. Biochem Biophys Res Commun 2008;372:336-340.

51 Simko V, Takacova M, Debreova M, Laposova K, Ondriskova-Panisova E, Pastorekova S, Csaderova L, Pastorek J: Dexamethasone downregulates expression of carbonic anhydrase IX via HIF- $1 \alpha$ and NF- $\kappa B-$ dependent mechanisms. Int J Oncol 2016;49:1277-1288. 